\title{
A New Chapter for Child Psychiatry and Human Development: Building on Strength
}

\author{
Eric A. Storch ${ }^{1}$ \\ Published online: 18 November 2019 \\ ○) Springer Science+Business Media, LLC, part of Springer Nature 2019
}

With both honor and tremendous enthusiasm, I am pleased to assume the reins from Dr. Ken Tarnowski as Editor-inChief of Child Psychiatry and Human Development. About 10 years ago, Dr. Tarnowski approached me about joining the editorial board of Child Psychiatry and Human Development which later expanded into a role as Associate Editor. I am forever grateful for this opportunity as this was my initial opportunity to engage in the editing process at a high level while learning from one of the best.

Dr. Tarkowski is what is described in both baseball and academia as a 'triple threat'-the rare combination of expertise in educational, research, and clinical realms. He has plied his trade at several top institutions, serving as a leader in pediatric psychology. This includes his current position at Florida Gulf Coast University where he held a variety of leadership positions as one of the few tenured faculty on campus. During this time, he took over as Editorin-Chief of Child Psychiatry and Human Development as well as the journal Children's Health Care. Child Psychiatry and Human Development, which has a storied reputation since 1970, developed into a very solid journal for studies in child psychology and psychiatry. Under his leadership, Child Psychiatry and Human Development has published numerous high-quality manuscripts and witnessed its impact factor steadily rise. Child Psychiatry and Human Development indeed has become a leading international outlet for the dissemination of scholarship.

Beyond establishing Child Psychiatry and Human Development as a leading journal, much of Dr. Tarnowski's legacy sits in what he did behind the scenes. Dr. Tarnowski has provided numerous early career psychologists and psychiatrists the opportunity to become engaged at the editorial board and Associate Editor levels. Indeed, the team of Associate

Eric A. Storch

Eric.Storch@bcm.edu

1 Menninger Department of Psychiatry \& Behavioral

Sciences, Baylor College of Medicine, Houston, USA
Editors is world class including Drs. Rebecca Ang, Catherine Epkins, Lara Farrell, Adam Lewin, Peter Muris, Kirti Saxena, and Louis Schmidt. Our team is likewise supported by an equally impressive team at Springer Nature including Senior Editor Jennifer Hadley and Journal Editorial Assistant Kokila Kothandaraman. Dr. Tarnowski's dedication to high-quality science and furthering the next generation of clinician-scientists-whether it be within his institution or outside-is remarkable. As he continues in the next chapter of his career, it is comforting to know that this passion for supporting others will continue and is a torch I also will continue to carry.

Child Psychiatry and Human Development has never been stronger; the focus will continue to involve publishing strong science in the fields of child and adolescent psychology and psychiatry. We will also continue to engage early and mid-career scientists who comprise the editorial team, including additional members of our international editorial board. Finally, we will also look for opportunities for innovative special issues and the potential of new article types. More to come over the coming months!

Dr. Tarnowski is leaving his role as Editor-in-Chief of Child Psychiatry and Human Development with the journal in tremendous shape. It is my hope to continue Dr. Tarnowski's success of publishing sound science and scholarship as well as engaging the broader community. Like my predecessor, I will be open and available to our readership regarding feedback and opportunities for adapting to the field. I look forward to serving in this role and am so very grateful for the opportunity and mentorship provided by my friend, the outgoing editor.

Publisher's Note Springer Nature remains neutral with regard to jurisdictional claims in published maps and institutional affiliations. 